\title{
The Effect of News Shocks and Monetary Policy*
}

\author{
Luca Gambetti ${ }^{\dagger}$ \\ Universitat Autònoma \\ de Barcelona \\ John D. Tsoukalas ${ }^{\S}$ \\ Francesco Zanetti $₫$ \\ University of Glasgow \\ Dimitris Korobilis ${ }^{\ddagger}$ \\ University of Essex \\ University of Oxford
}

September 2017

\begin{abstract}
A VAR model estimated on U.S. data before and after 1980 documents systematic differences in the response of short- and long-term interest rates, corporate bond spreads and durable spending to news TFP shocks. Interest rates across the maturity spectrum broadly increase in the pre-1980s and broadly decline in the post-1980s. Corporate bond spreads decline significantly, and durable spending rises significantly in the post-1980 period while the opposite short-run response is observed in the pre-1980 period. Measuring expectations of future monetary policy rates conditional on a news shock suggests that the Federal Reserve has adopted a restrictive stance before the 1980s with the goal of retaining control over inflation while adopting a neutral/accommodative stance in the post-1980 period.
\end{abstract}

Keywords: News shocks, Business cycles, VAR models, DSGE models

JEL Classification: E20, E32, E43, E52

\footnotetext{
*We thank Paul Beaudry, Jean-Guillaume Sahuc and seminar participants at the Banque de France and the University of Oxford for extremely valuable comments. Some of this work was completed while John Tsoukalas and Francesco Zanetti were visiting scholars at the Banque de France; they would like to thank the Foundation Banque de France for its support. Financial support from the Leverhulme Trust Research Project Grant RPG-2014-255 is gratefully acknowledged.

${ }^{\dagger}$ Departament d'Economia i d'Historia Economica, 08193 Bellaterra, Spain.

${ }^{\ddagger}$ Essex Business School, Wivenhoe Park, Colchester, CO4 3SQ, U.K.

$\S$ Adam Smith Business School, Gilbert Scott Building, Glasgow, G12 8QQ, U.K.

`Department of Economics, Manor Road, Oxford, OX1 3UQ, U.K.
} 


\section{Introduction}

The effect of anticipated changes in future total factor productivity (TFP) - the so-called news shocks - on current macroeconomic outcomes has spurred considerable research interest over the past few years. Several studies find that news shocks exert strong influence on expectations about future economic conditions and thus lead to sizable changes in current economic activity. ${ }^{1}$ This paper establishes new empirical facts about changes in the transmission and propagation of news shocks over time and finds that they are tightly linked to systematic changes in the conduct of monetary policy.

To isolate differences in the effect of news shocks across time, we estimate a vector autoregression (VAR) model on two subsamples of U.S. data, before and after 1980 . We apply the identification approach in Forni et al. (2014), whereby a TFP news shock best anticipates TFP in the long run without changing current TFP. ${ }^{2}$ We find that responses of nominal short- and long-term interest rates to a news TFP shock exhibit a sign reversal between subperiods. A positive news TFP shock is associated with a delayed rise in short- and long-term nominal interest rates before the 1980s. By contrast, the same shock is associated with a fall in these same rates after the 1980s. We investigate whether these sharp sign reversals in the response of nominal rates are related to systematic differences in the conduct of monetary policy using the Expectation Hypothesis as our organizing framework. The Expectation Hypothesis postulates that long-term interest rates are approximated by an expectation component derived from the weighted average of current and future short-term interest rates plus an error component that encapsulates risk premia. The expectation component provides a powerful reading on the conduct of monetary policy and expectations about the full range of future policy rates. We find that the sign reversals are echoed by similar shifts in the response

\footnotetext{
${ }^{1}$ See Beaudry and Portier (2014) and references therein for a comprehensive review of the literature.

${ }^{2}$ In section 2, we discuss the relationship of our identification method with alternative approaches.
} 
of the expectations component in the term structure of policy yields inferred from the Expectation Hypothesis. The VAR model shows that the expectations component of long-term rates rises persistently in response to the anticipated increase in TFP in the pre-1980 period and declines persistently in the post-1980 period. These findings are robust to alternative maturities of bond yields. Important for the analysis, the residual component of the long-term interest rates remains statistically unchanged between subperiods, suggesting that risk premia play no role for the systematic differences in the response of the term structure of policy yields to the news shock.

These findings consistently point to substantial changes in the systematic response of monetary policy to anticipated changes in TFP before and after the 1980s. We find that systematic changes in the response of policy yields, as identified by the expectations hypothesis, are mirrored by a similar reversal in the response of real interest rates, as well as real and financial variables to news shocks between subperiods. Real interest rates broadly maintain the sign reversal of nominal yields; namely, they rise in the first subperiod and fall in the second subperiod. Current economic activity, hours worked, investment and consumer durable spending decline on impact and closely track movements in observed TFP in the pre-1980 period whereas they sharply increase on impact and anticipate the future rise in TFP several years ahead in the post-1980 period. These findings are consistent with the logic of the standard Euler equation, where the entire path of real interest rates is inversely related to spending decisions, especially for investment and durables spending. Corporate bond spreads, which proxy financial conditions following an emerging literature, rise somewhat in the first subperiod and decline in the second subperiod, consistent with the effect of the news shock on real activity. $^{3}$

\footnotetext{
${ }^{3}$ See Gilchrist and Zakrajsek (2012) for a treatment of financial conditions and relation with corporate bond spreads, Görtz et al. (2016), and Görtz and Tsoukalas (2017) for a discussion of the role of financial markets for the propagation of news shocks.
} 
What is the explanation for these systematic differences in the response of policy rates and the consequent changes in the propagation of news shocks across real and financial variables? A wide range of influential research shows that anchoring inflation expectations helps the central bank stabilize current inflation without requiring sharp adjustments in the policy rate. ${ }^{4}$ To the extent that large and persistent movements in inflation cannot occur without substantial changes in monetary policy, we can glean information about variations in the conduct of monetary policy from the differences in the responses of inflation and inflation expectations to anticipated changes in TFP. The reaction of inflation expectations to the TFP news shock is significantly different between subsamples even though the TFP news shock produces a similar impact decline in actual inflation in both subsamples. In the first subsample, inflation expectations increase despite a decline in actual inflation. The rise in inflation expectations coincides with a delayed increase in economic activity generated by the news shock. By contrast, in the second subsample, the decline in expected inflation resembles the fall in actual inflation, despite an immediate and strong increase in economic activity. Evidently, the increase in real activity triggered by the TFP news shock feeds into higher inflation expectations in the first subperiod but not the second.

The stark change in the response of policy yields is tightly related to the variation in the remit of monetary policy between subperiods. Policy rates in the pre-1980s closely track economic activity as a result of the "lean-against-the-wind" stance of chairman William McChensey Martin who presided over most of this period (1951-1970). During this time, the Fed was concerned that expansionary movements in economic activity may generate a sharp rise in inflation given the limited influence over inflation expectations. By contrast, in the post-1980s, the Fed received a dual mandate to achieve maximum employment, stable prices, and moderate long-term interest rates, becoming legally

\footnotetext{
${ }^{4}$ See Gertler et al. (1999), Svensson (2010) and references therein.
} 
liable to maintain stable inflation. ${ }^{5}$ Under the chairmanships of Volcker, Greenspan and Bernanke (1979-2014), the Fed effectively anchors inflation expectations, therefore remaining unconcerned that good news about productivity may generate inflationary pressures - even though they stimulate economic activity on impact. Our results are in line with this intuition: the news TFP shock is associated with a persistent and mild fall in inflation expectations. The response of the Fed, in contrast to the first subperiod, is not to restrict the immediate rise in economic activity in the aftermath of the news shock by raising the policy rate. Our findings are consistent with these systematic changes in the conduct of monetary policy over time. Thus, post-1980s evidence suggests that the Fed allowed the nominal interest rate to decline in a quest to curb the fall in actual inflation since it was able to credibly and effectively manage inflation expectations. ${ }^{6}$

Our analysis relates to several studies focused on the effect of news shocks. Beaudry and Portier (2004), Karnizova (2010), Fujiwara et al. (2011), Milani (2011), SchmittGrohe and Uribe (2012), Ben Zeev and Khan (2015), Barsky and Sims (2011), Kurmann and Otrok (2013) and Theodoridis and Zanetti (2016) show that anticipated movements in future TFP have an important effect on current macroeconomic fluctuations. Our study is the first to detect temporal variation in the effect of TFP news shocks and establish that these differences are related to changes in the conduct of monetary policy over time. In this respect, our analysis also contributes to the large body of research on the changes of the effect of exogenous shocks on macroeconomic outcomes. Benati (2004) and Bianchi et al. (2009) detect important time variation in economic performance

\footnotetext{
${ }^{5}$ See the Federal Reserve Act (ch. 6, 38 Stat. 251, enacted December 23, 1913, 12 U.S.C. ch. 3). In 1977, Congress amended the Federal Reserve Act, directing the Board of Governors of the Federal Reserve System and the Federal Open Market Committee to "...maintain long run growth of the monetary and credit aggregates commensurate with the economy's long run potential to increase production, so as to promote effectively the goals of maximum employment, stable prices and moderate long-term interest rates." See Goodfriend and King (2005) for an economic account of the new monetary policy framework.

${ }^{6}$ An influential study by Gertler et al. (1999) shows that monetary policy can effectively influence the economy by managing inflation expectations in addition to using changes in the policy rate.
} 
related to changes in the monetary policy framework across time. Mumtaz and Surico (2012) show global changes in the persistence and level of inflation since the 1980s that can be explained by changes in the conduct of monetary policy and the onset of globalization. Gambetti and Gali (2009) show that important co-movements among output, hours and productivity significantly changed over the postwar period. Liu et al. (2017) find important variation in the effect of monetary policy shocks during the economy transit between different economic regimes. Finally, our results also relate to the large literature on the effect of monetary policy for macroeconomic fluctuations. Influential studies by Gertler et al. (1999), Ireland (2000, 2003, 2007), Boivin and Giannoni (2006) and Castelnuovo (2012) show that the effect of exogenous shocks on the economy depends on the stance of monetary policy. Our analysis provides novel empirical evidence on the critical role of monetary policy for the propagation of anticipated changes in TFP on the economy, which is consistent with changes in the conduct of U.S. monetary policy over the postwar period.

The remainder of the paper is organized as follows. Section 2 presents data and lays out the VAR model and the identification strategy. Section 3 discusses new facts on the propagation of news shocks over time as well as investigates the sources of systematic differences in the response of interest rates and macroeconomic indicators. Section 4 presents our conclusion.

\section{Data and the VAR model}

This section describes the data, subperiods and identification methodology.

Data. We estimate the VAR model using quarterly U.S. data for the period 1954:Q3-2013:Q4. We examine several different VAR specifications with the aim of establishing robust and comprehensive facts about the response of a host of measures 
of economic activity, interest rates, prices, financial and survey indicators to TFP news shocks. Each VAR specification features seven variables. A key input is an observable measure of TFP. For this purpose, we use the aggregate TFP measure in Fernald (2012), which is based on the growth accounting methodology in Basu et al. (2006) and corrects for unobserved capacity utilization. ${ }^{7}$ In addition to the standard macro indicators used in previous studies - namely, output, consumption, investment, and hours workedwe incorporate information from three measures of long-term rates, specifically onefive- and ten-year government bond yields. Our measure of inflation expectations is the expected one-year-ahead inflation from the Michigan survey. We also use personal consumption expenditures on durables and the Michigan survey expectations and buying intention on durables, housing and vehicles. To estimate the model, we apply four lags with a Minnesota prior and compute confidence bands by drawing from the posterior. Appendix B provides details on the specification of the prior.

Subperiods. A large number of studies has convincingly noted a significant change in the dynamic properties of several U.S. macroeconomic variables before and after the mid-1980s. Moreover, a fundamental change in Federal Reserve policy is widely believed to have occurred soon after Paul Volcker's appointment as chairman in August 1979. Additionally, numerous studies show that monetary policy has become more responsive to movements in inflation in the post-1980 period. See Taylor (1993) and Clarida et al. (2000), among others. Following the findings in the literature, the full sample period is divided into two disjointed subsamples: the first runs from 1954:Q3 through 1979:Q2 and corresponds to the chairmanships of Martin and Burns (and a very short tenure of Mitchell), and the second runs from 1982:Q3 through 2013:Q4, corresponding to the chairmanships of Volcker, Greenspan and Bernanke. We remove the period 1979:Q3-

\footnotetext{
${ }^{7}$ Throughout the paper, we use the 2015 vintage of TFP that incorporates new updated corrections in the utilization estimates based on Basu et al. (2010).
} 
1982:Q2 from our analysis because of unusual operating procedures that were effective during that episode. ${ }^{8}$

Identification methodology. To identify the TFP news shock using the VAR model, we adopt the identification scheme of Forni et al. (2014). Specifically, we assume that the news shock does not move TFP on impact and has maximal impact on TFP in the long run (at the 40-quarter horizon). ${ }^{9}$ We also explore the robustness of our results using the alternative approach proposed by Neville et al. (2014), which identifies the news shock as the shock that maximizes the fraction of the variance in TFP at a specific long but finite horizon. ${ }^{10}$

\section{Results}

Figures 1 and 2 display the impulse response functions (IRFs) to a positive TFP news shock for the pre- and post-1980 period, respectively. They focus on the IRFs of TFP, three activity variables: inflation as measured from the GDP deflator, the five-year bond yield and the three-month T-bill rate. We find a zero impact response of TFP to the news shock by construction and a gradual increase to a permanently higher level that captures a permanent diffusion process of technology anticipated by agents in the economy. This dynamic response is consistent with the original idea of a news shock in Pigou (1926) and corroborates the recent assessments of the TFP response to a news shock outlined in

\footnotetext{
${ }^{8}$ Bernanke and Mihov (1998) provide formal evidence on the idiosyncracy of that period.

${ }^{9}$ Barsky and Sims (2011) propose an alternative identification strategy that considers all shocks that are orthogonal to the innovation in current productivity. Among these, they select the shock that maximally explains a weighted average of future levels of productivity. In a subsequent paper, Barsky et al. (2015) report: "The maximization-based identification in Barsky and Sims is not entirely transparent, and there is an arbitrariness (inherited from Uhlig (2004)) about the weights attached to the various horizons over which technology shocks are to be explained." Thus, we prefer to use alternative identification methods.

${ }^{10}$ These results are qualitatively and quantitatively similar to the results reported in the paper using Forni et al. (2014). We do not report them due to space considerations, but they are available on request.
} 
Beaudry and Portier (2014). The long-run increase in TFP is approximately 1 percent in both subperiods. The observation that the response of TFP in the long run to the news shock is nearly identical across subperiods, is important for our analysis. We interpret the dynamic response of TFP to the news shock and the strong quantitative similarity in the medium (beyond the 20-quarter horizon) to long run across subperiods as compelling evidence that our identification scheme effectively and consistently identifies TFP news shocks across subperiods.

The short-run response of the two real activity variables - namely, output, and hours worked - shows a marked difference across subperiods. The impact response of hours is negative in the first sample. The impact response of output varies significantly across subperiods, being insignificantly different from zero in the first subsample and significantly positive in the second subsample. The response of consumption, measured by consumption expenditures in non-durables and services, is broadly similar across the two subperiods. But important to our analysis, as we illustrate in section 3, the shortrun response of private investment and consumer durables differs significantly across subsamples. These differences account, at least qualitatively, for the different short-run output responses to the news TFP observed across the two subperiods. The response of inflation is negative in both subperiods. However, inflation picks up and becomes mildly positive at approximately the three-year horizon in the first subperiod whereas it quickly returns to zero in the second subperiod. Importantly, the timing in the rise of inflation during the first sample coincides with the strong increase in output and hours in that subsample. The response of inflation in the second subperiod is in line with conventional wisdom: namely, inflation is forward looking and responsive to changes in real marginal costs brought about the future increase in TFP. This finding generalizes and corroborates the results in Barsky et al. (2015) and Christiano et al. (2010) that also detect a strong disinflationary effect of news shocks. However, the behavior of inflation 
in the first subperiod is difficult to square with this view since the increase in inflation occurs at a time when TFP is already approaching the new higher long-run level that in principle stimulates a reduction in inflation. We discuss this issue in more detail when we examine and contrast the behavior of realized inflation with expectations of inflation. The transitional dynamics of variables differ across subperiods. In the first subperiod, output and hours worked closely track the path of TFP beyond the very short run. By contrast, in the second subperiod, the same variables swiftly respond on impact in the anticipation of the foreseen increase in TFP, even though the latter begins to increase beyond two years. Overall, responses of macro aggregates in the second subperiod are consistent with the traditional view of TFP news shocks, as articulated in Beaudry and Portier (2006).

Long- and short-term interest rates. The comparison across subperiods pinpoints some striking and systematic differences in the responses of short- and longterm interest rates that indicate important differences in the conduct of monetary policy across subperiods. Figures 1 and 2 display responses to the three-month Treasury bill rate and five-year government bond yield. In the pre-1980 period, the response in the short-term nominal interest rate (TB3) tracks the reaction of output closely; that is, it is statistically indifferent from zero for the initial 12 quarters, gradually rising and becoming significantly positive thereafter. Importantly, the peak response in the nominal rate coincides with the peak in the responses of output and hours. The response of the long-term nominal interest rate $(5 \mathrm{Y})$ is similar to the reaction of the short-term nominal interest rate; that is, it is not statistically different from zero (except a brief period) for the first 18 quarters and then significantly rises and remains elevated thereafter. ${ }^{11}$ By contrast, in the post-1980 period, the median response of the short-term nominal interest

\footnotetext{
${ }^{11}$ The significant brief short-run decline in the long-term rate is driven by a decline in the term premium. See Figures 5 and 6.
} 

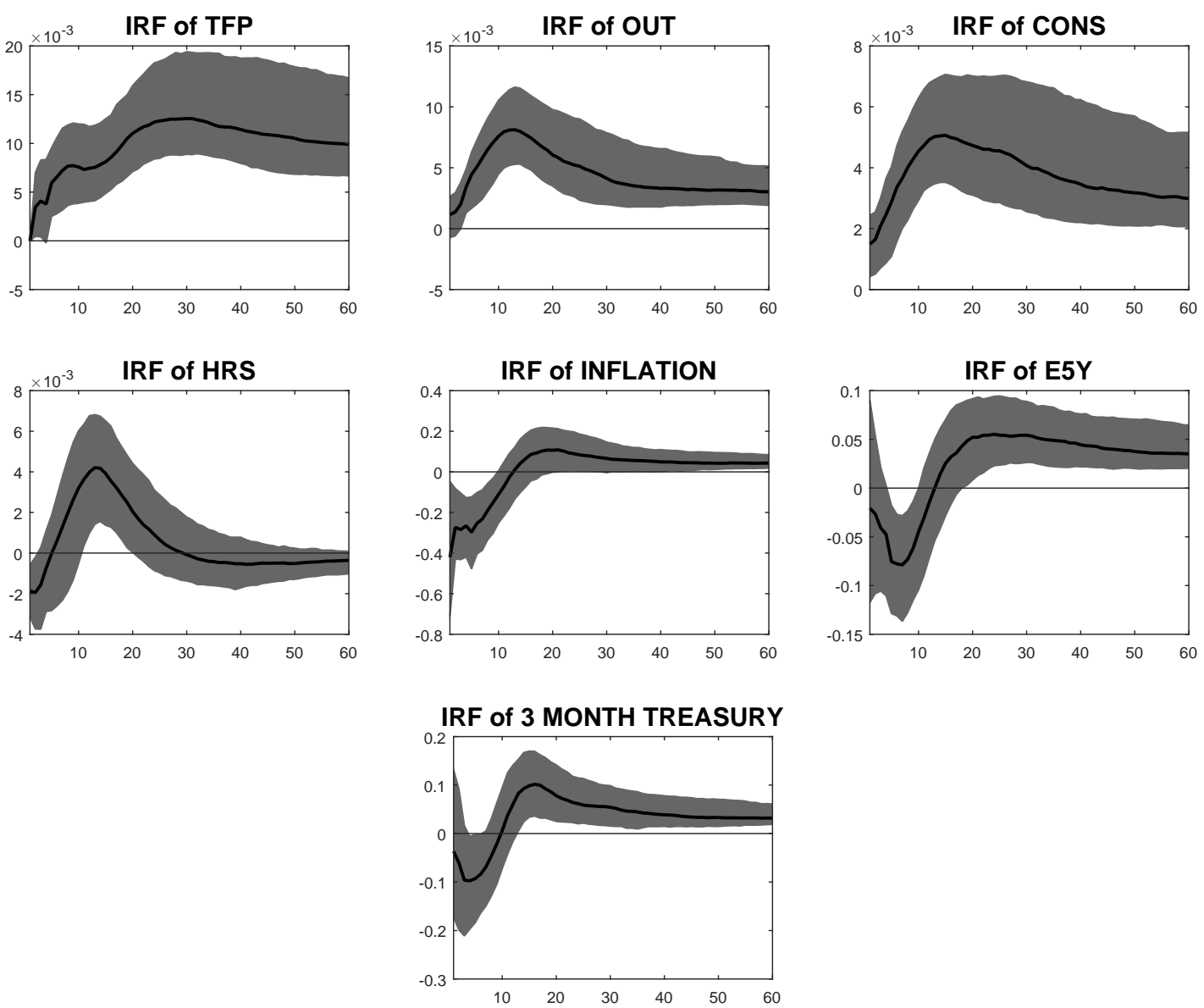

Figure 1: First sample (1954:Q3-1979:Q2). The solid line is the median estimated impulse response (in percent) to a positive TFP news shock from a seven variable VAR featuring TFP, output, hours, investment, inflation, 5-year bond yield and 3-month T-bill rate estimated with 4 lags. Shaded areas indicate the $16 \%$ and $84 \%$ confidence bands. 

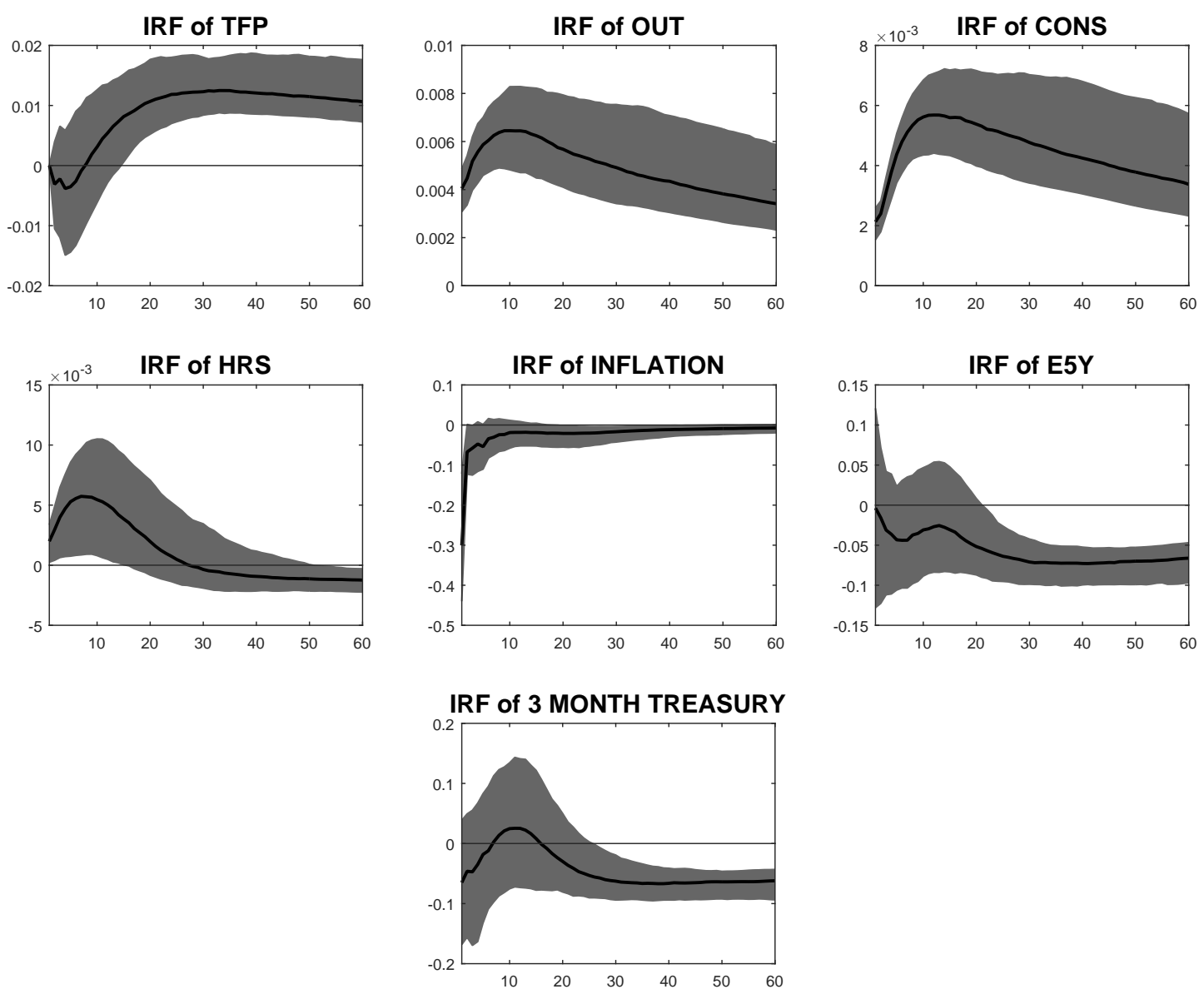

Figure 2: Second sample (1982:Q3-2013:Q4). The solid line is the median estimated impulse response (in percent) to a positive TFP news shock from a seven variable VAR featuring TFP, output, hours, investment, inflation, 5-year bond yield and 3-month T-bill rate estimated with 4 lags. Shaded areas indicate the $16 \%$ and $84 \%$ confidence bands. 
rate is negative and becomes significant from approximately the 20-quarter horizon. The response of the long-term nominal interest rate is negative (and statistically significant after the first 20 quarters) in all horizons.

To investigate whether alternative maturities of short- and long-term rates exhibit similar differences across subperiods, Figures 3 and 4 display IRFs of several shortand long-term rates to a positive TFP news shock for the pre- and post-1980 periods, respectively. The responses are generated from VAR specifications where we condition the analysis on the same set of variables as those displayed in Figures 1 and 2, but where we replace the five-year yield with either the one-year or 10-year yield, and where we replace the three-month Treasury bill rate with the Fed funds rate. The responses of the one-year, five-year and 10-year yields are consistent with each other in each sub-sample. Figure 3 shows that in the first subperiod, long-term interest rates exhibit a persistent rise after a short-lived decline. In the first subsample, the response of the long-term rates mimics the response of the short rates to a great extent, suggesting that bond markets expect short rates to stay persistently elevated. The response of short-term interest rates suggests a restrictive stance adopted by the Fed, which, as explained above, coincides with the pick-up in real activity documented in Figure 1. Figure 4 by contrast suggests a distinctively different pattern in the responses of long- and short-term interest rates. Both short and long rates exhibit a decline beyond the very short run following the news TFP shock. The median response of five- and ten-year bond yields is negative across all horizons and becomes statistically significant with a delay. The ten-year short-term rates captured in the three-month T-bill and Fed funds rate exhibit initially an insignificant response, followed by a decline that is statistically significant. Overall, the responses of short- and long-term rates in the second period is consistent with a short-run neutral interest rate that becomes progressively more accommodative (or looser) policy stance.

Expectation Hypothesis and term premia. The VAR results point to 

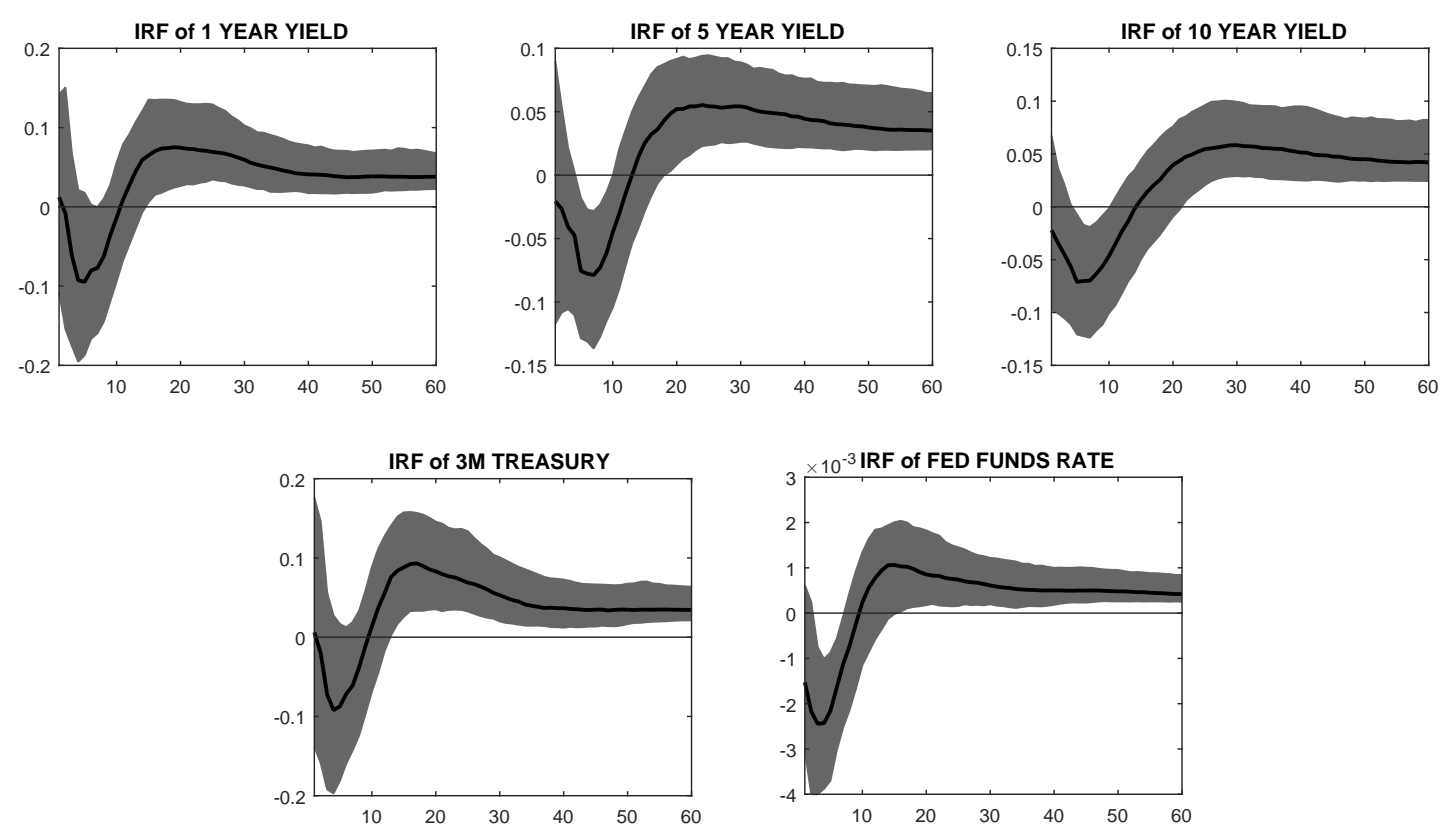

Figure 3: First sample (1954:Q3-1979:Q2) — long- and short-term rates. The solid line is the median estimated impulse response (in percent) to a positive TFP news shock. Shaded areas indicate the $16 \%$ and $84 \%$ confidence bands.
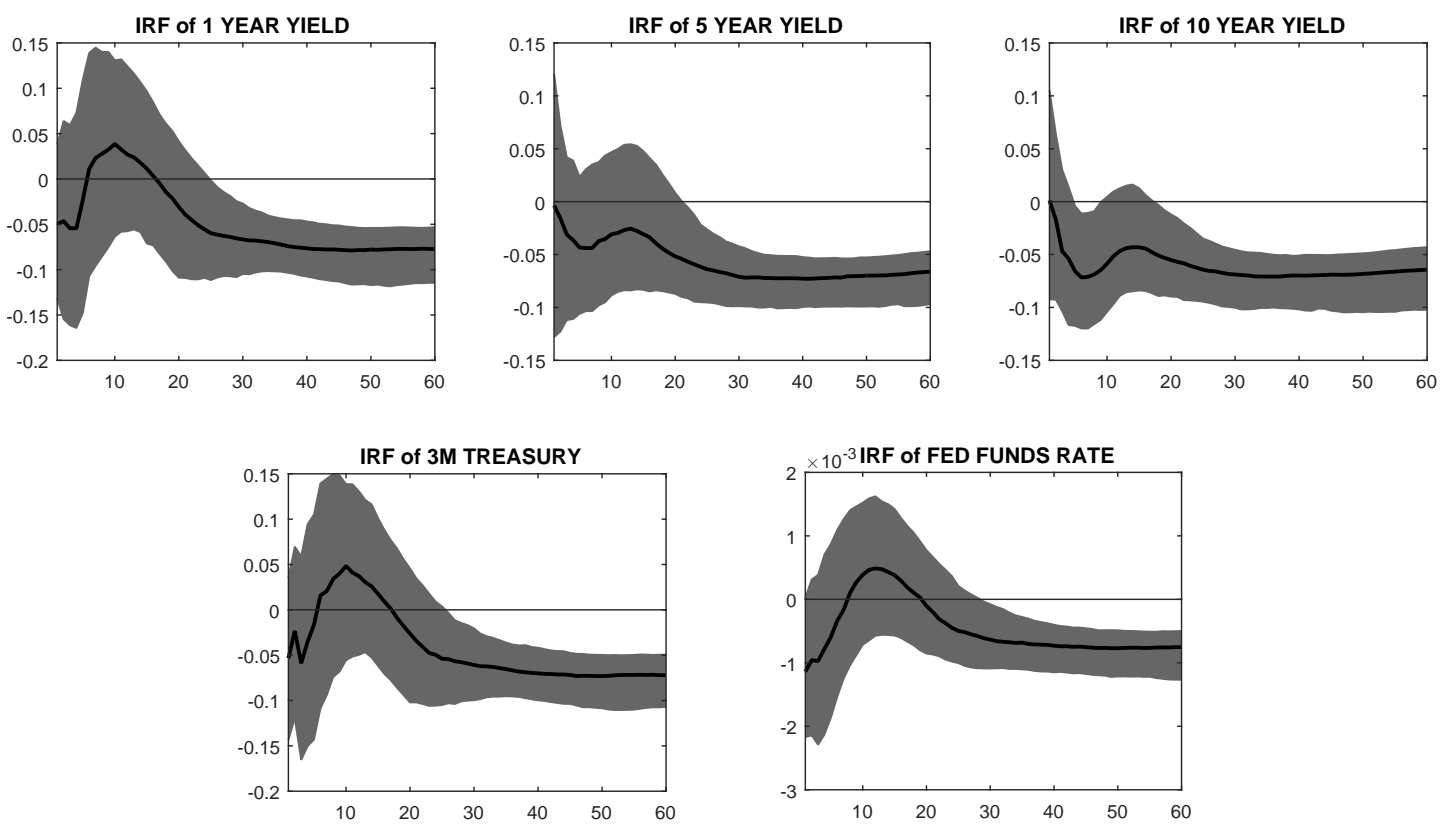

Figure 4: Second sample (1982:Q3-2013:Q4) - long- and short-term rates. The solid line is the median estimated impulse response (in percent) to a positive TFP news shock. Shaded areas indicate the $16 \%$ and $84 \%$ confidence bands. 
systematic changes in a number of different maturity interest rates and some changes in the reaction of macroeconomic variables - namely, output and hours worked to TFP news shocks. To investigate whether differences in the responses of interest rates with different maturities reflect systematic changes in the conduct of monetary policy, we assess the reaction of the expectations component of the long-term interest rate using the Expectation Hypothesis of interest rates.

We use the Expectations Hypothesis (EH) to produce a measure of the expected future conduct of monetary policy. The EH postulates that long-term interest rates are proxied by a weighted average of current and future short-term interest rates. This metric provides a powerful reading on expectations about the whole range of future policy rates and therefore conveys a broad appraisal on the overall expected stance of monetary policy. We compute a synthetic ten-year long rate from the $\mathrm{EH}$ as the weighted sum of present and expected short-term interest rates. ${ }^{12}$ Specifically,

$$
i_{t}^{40}=i_{t}+\frac{1}{40} \sum_{j=0}^{39}\left[\left(1-\frac{j}{40}\right) E\left(\Delta i_{t+j} \mid Y_{t}\right)\right],
$$

where $E\left(\Delta i_{t+j} \mid Y_{t}\right)$ is the future expected path of interest rates as implied by the VAR model, based on the information set $Y_{t}$, where we use the three-month T-bill as our measure of the short-term rate. ${ }^{13}$ Equation (1) is only approximate since there are deviations between the actual and synthetic ten-year rates, which are captured by the term premium. The term premium is calculated as the difference between the observed 10-year, long-term interest rate and the corresponding 10-year, long-term rate computed from the EH (denoted LEH) (i.e., term premium = 10-year rate - LEH). Examining the behavior of the term premium is important. It allows us to establish the extent

\footnotetext{
${ }^{12}$ Results are robust to the five-year long rate. An appendix that details robustness of the findings is available on request to the authors.

${ }^{13}$ Results are robust to the use of the Federal Funds rate as the measure of the short-term rate.
} 
to which the observed actual response of long-term rates to the news shock is driven by movements in the systematic conduct of monetary policy vis-a-vis movements in the term premium.

Figures 5 and 6 display the decomposition of the long-term rate into the response of the LEH and the term premium. Consistent with results on short- and long-term interest rates displayed in Figures 3 and 4, the response of the systematic component of the long-term rate, LEH, differs significantly across the two subperiods. The VAR model shows that the LEH component rises persistently in response to the anticipated increase in TFP in the pre-1980 period. By contrast, the LEH component declines persistently in response to the same anticipated TFP increase in the post-1980 period. Moreover, as evidenced by the response of the term premium, in the first subperiod, the short-run decline in the realized ten-year rate is entirely due to the decline in the former. Interestingly, the decomposition indicates that movements in the term premia cannot be important drivers of the decline of the long-term rate in the second subsample since the response of the term premium remains insignificant throughout. But beyond these short-run movements, the responses of the long-term rate are dominated by the systematic component of policy as suggested by the EH. Therefore movements in the term premia cannot account for the differential effects of news shocks on the observed long-term rates. These distinctive differences in the systematic policy component of the long-term interest rate indicate the role of monetary policy in the different propagation of the TFP news shock.

Real interest rates, durables spending and financial variables. The analysis shows that systematic changes in the response of policy yields are echoed by changes in the response of real interest rates and real and financial variables to news shocks between subperiods. Figures 7 and 8 display IRFs to private domestic investment, consumer durables, the three-month (realized) real interest rate (computed as the three- 

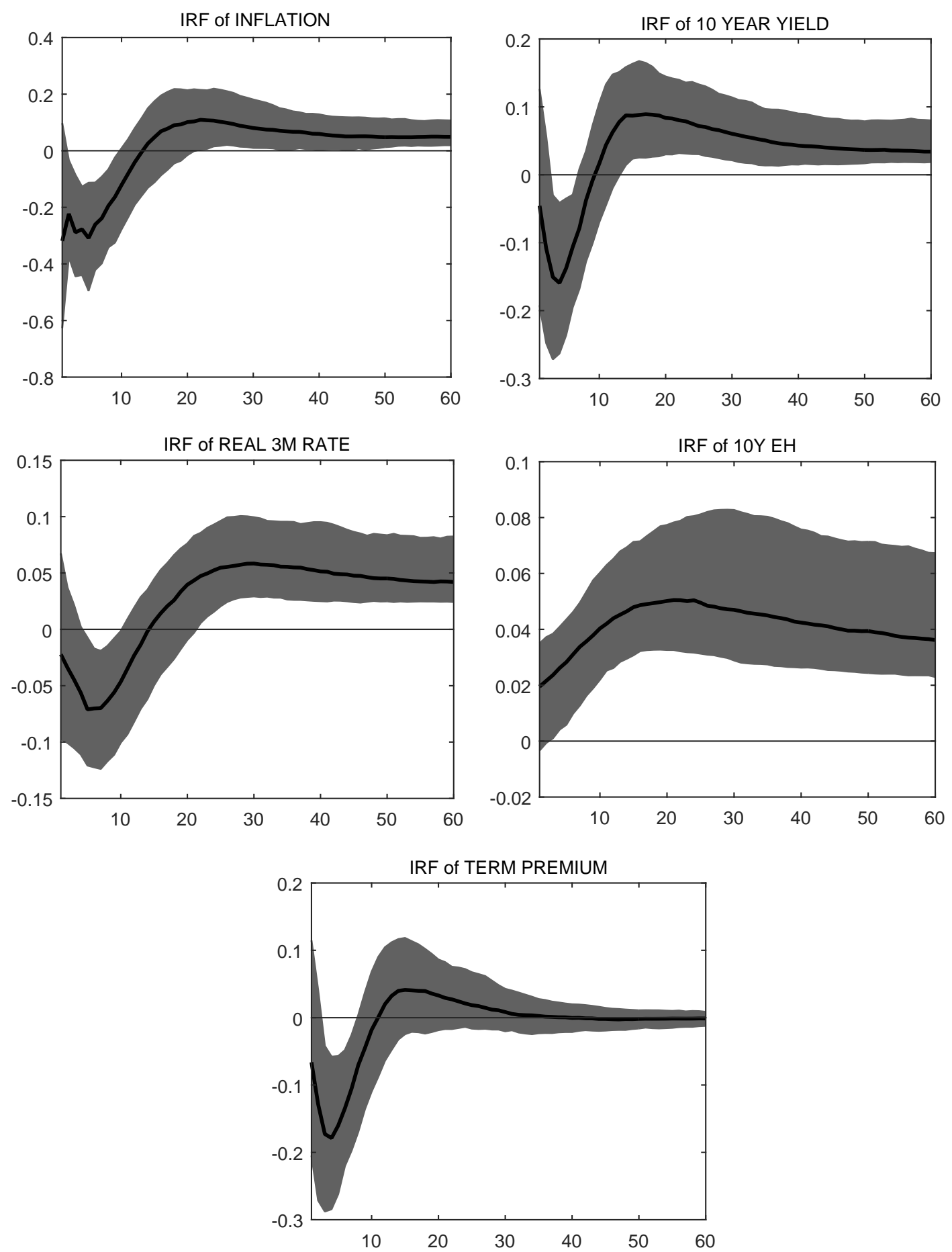

Figure 5: First sample (1954:Q3-1979:Q2)-decomposition of interest rates. The solid line is the median estimated impulse response (in percent) to a positive TFP news shock. Shaded areas indicate the $16 \%$ and $84 \%$ confidence bands. 

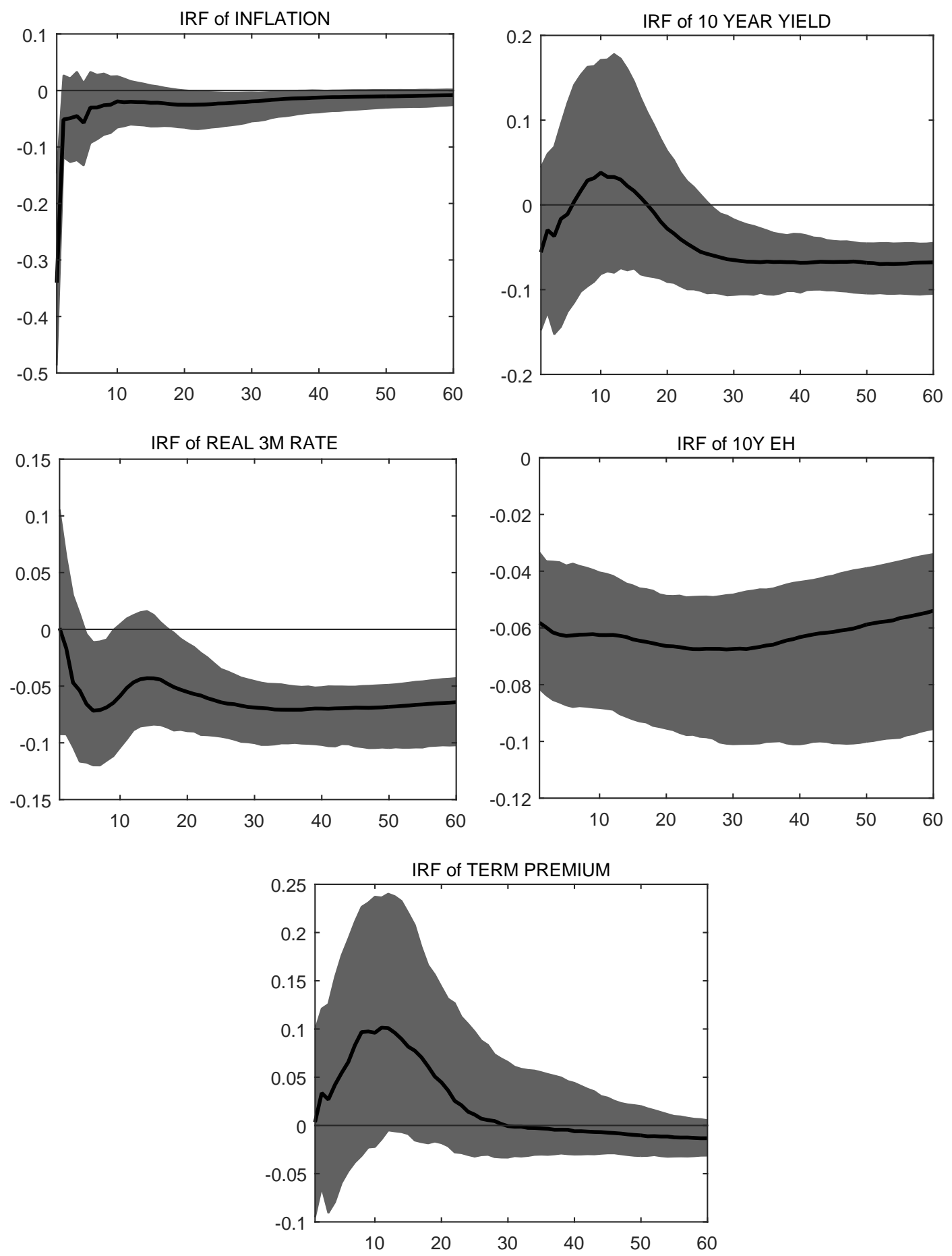

Figure 6: Second sample (1982:Q3-2013:Q4)-decomposition of interest rates. The solid line is the median estimated impulse response (in percent) to a positive TFP news shock. Shaded areas indicate the $16 \%$ and $84 \%$ confidence bands. 
month Treasury bill rate minus actual inflation) and the BAA-AAA corporate bond spread in the first and second sample, respectively. Private domestic investment includes spending of consumer durables. However, we plot the IRF of the latter separately to highlight the different response of this component of consumption relative to the non-durables component of consumption shown in Figures 1 and 2. The responses of private domestic investment and corporate spread are obtained from a VAR specification conditioned on the same information as the one in Figures 1 and 2, except that we drop the five-year yield and the three-month Treasury bill rate and replace them with the aforementioned variables. The responses of consumer durables and real interest rate are generated in the same fashion. Several findings are worth noting. In the first subperiod, the impact responses of private investment and consumer durables are significantly negative. These responses eventually turn positive and display a path similar to the activity indicators shown in Figure 1. By contrast, in the second subperiod, the impact responses of the same activity variables are strongly positive. In the first subperiod, the response of the real interest rate is positive for almost 20 quarters before it returns to zero. In the second subperiod, by contrast, while initially the median response is positive (though insignificant), it becomes negative from approximately 20 quarters onwards. The response of the real interest rate in the two subperiods is consistent with the reaction of the short-term nominal interest rate shown in Figures 1 and 2. The path of the real rate indicates a restrictive policy stance in the first subperiod and a neutral and ultimately looser policy stance in the second subperiod. Finally, in the first subperiod, the impact response of the corporate bond spread is positive (though not statistically significant), suggesting a mild, initial tightening of financial conditions in the corporate debt market. In the second subperiod, the response of the corporate spread is significantly negative, suggesting a relaxation of financial conditions. Models with a role for financial frictions predict this type of negative correlation between investment 
and credit spreads. ${ }^{14}$

One important finding is the signalling role of the corporate bond market in the second subperiod. Corporate bonds immediately internalize the rise in future TFP and the profitability of new investment spending by easing financial conditions quickly. This immediate signalling effect fails to occur in the first subsample. If anything, financial markets play a very limited role in the short-run propagation of the news shock. Quantitatively, the negative response of the corporate spread in the second subsample is significantly stronger compared to the response in the first subsample (when the latter eventually declines). Similarly, the peak response of private investment is significantly stronger in the second subsample compared to the peak response in the first subsample (which occurs later). The last two observations corroborate the potentially important role played by financial markets for the propagation of the news shock in the second subsample. In the Appendix, we also examine the behavior of several indicators from the Michigan survey and Tobin's Q. The survey indicators relate to consumers' perceptions about buying conditions of durables, vehicles and housing, as well as the widely used five-year ahead consumer confidence. The responses of these indicators are consistent with the differential responses of investment and durables, namely that they rise immediately and significantly in the second subperiod, signalling good times ahead, but are insignificantly different from zero in the first subperiod.

Inflation expectations and monetary policy. What can explain these systematic differences in the conduct of monetary policy and the consequent changes in propagation across real and financial variables? A central finding in modern macroeconomic literature is that monetary policy exerts a strong influence on inflation expectations and that central banks use this channel to anchor inflation expectation to stabilize the economy (see Gertler et al. (1999) and references therein). By anchoring inflation expectations,

\footnotetext{
${ }^{14}$ See Gilchrist and Zakrajek (2012), Faust et al. (2013) and Görtz et al. (2016) and references therein.
} 

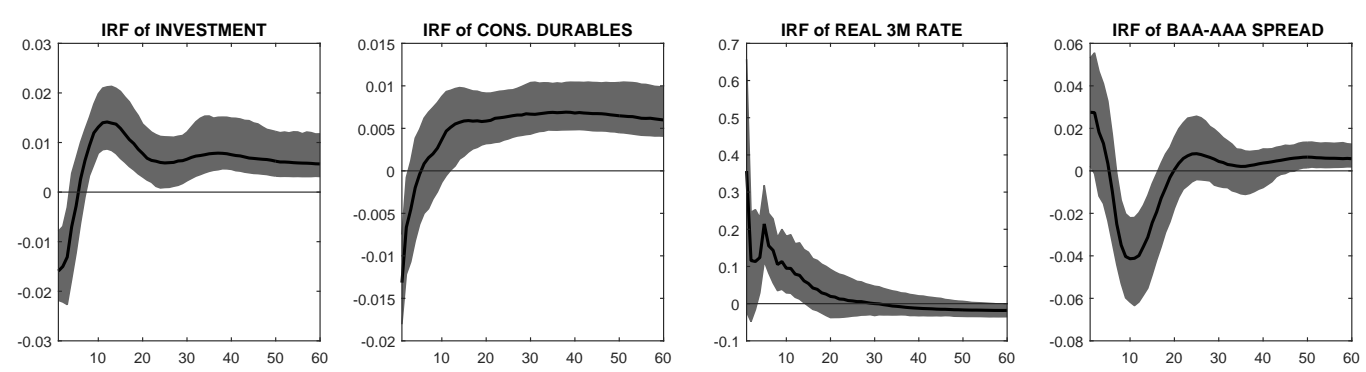

Figure 7: First sample (1954:Q3-1979:Q2). The solid line is the median estimated impulse response (in percent) to a positive TFP news shock. Shaded areas indicate the $16 \%$ and $84 \%$ confidence bands.
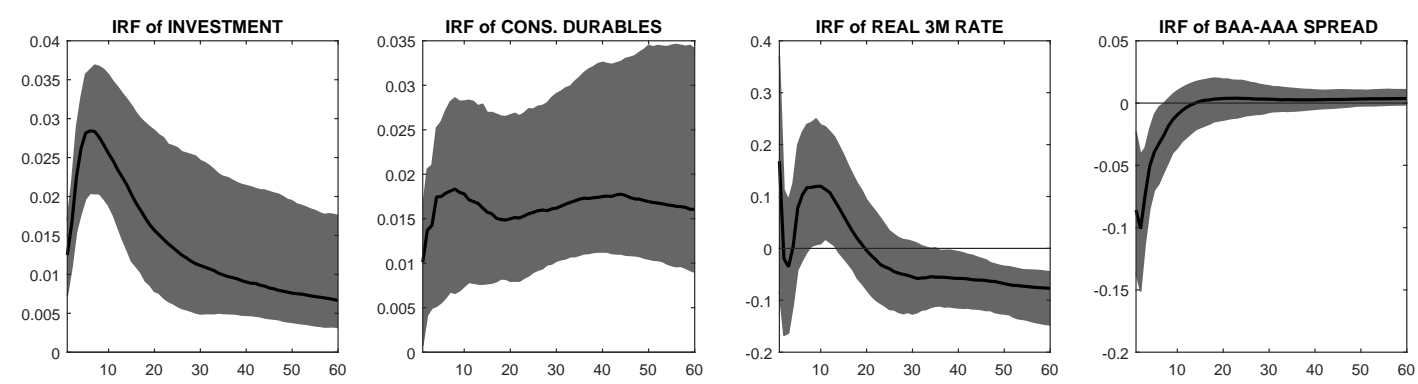

Figure 8: Second sample (1982:Q3-2013:Q4). The solid line is the median estimated impulse response (in percent) to a positive TFP news shock. Shaded areas indicate the $16 \%$ and $84 \%$ confidence bands.

the monetary authority retains control on current inflation without having to aggressively adjust the policy rate. These theoretical insights provide a powerful metric to detect systematic variations in the conduct of monetary policy across subperiods. To the extent that large and persistent movements in inflation cannot occur without substantial changes in monetary policy, we can glean information about variations in the conduct of monetary policy from the differences in the responses of inflation and inflation expectations to anticipated changes in TFP.

Figures 9 and 10 show the responses of current inflation and expected inflationmeasured by the one-year-ahead inflation expectations from the Michigan Survey of Consumers - to the TFP news shock before and after 1980, respectively. It also displays the IRFs of activity indicators and the Fed Funds rate. Two observations stand out. First, the responses of inflation expectations across the two subperiods are 
remarkably different. In the first subperiod, inflation expectations exhibit a decline in the short run similarly, although smaller in magnitude, to the decline in realised inflation. However, shortly after this decline, inflation expectations rise, suggesting that the public expects inflation to rise. Interestingly, the rise in inflation expectations occurs while realized inflation is still declining (at the 10-quarter horizon). The rise in inflation expectations coincides with the peak in economic activity, which occurs at the 10-quarter horizon. Inflation expectations remain consistently high thereafter; as long as activity remains strong (see the response of output), consumers seem to expect higher inflation. Interestingly, they seem to expect higher inflation permanently even as the economic boom subsides in the long run. This finding is interesting since it involves a concurrent increase in TFP, which could, with other things being equal, keep inflationary pressures in check. By contrast, in the second subperiod, expected inflation shows a small and persistent decline that returns to the initial state gradually while the actual inflation response has returned to zero by around the two-year horizon. The interesting finding in the second subperiod compared to the first one is that inflation expectations are decoupled from the boom in economic activity that is strong and immediate following the news TFP shock. Clearly, in the second subperiod, future growth in TFP is perceived as being disinflationary.

Changes in the conduct of monetary policy. To better understand these markedly different results across subperiods, it is important to relate the findings to the broader historical context of the conduct of monetary policy in the United States. The first subperiod broadly coincides with the term of governor William McChesney Martin, chairman of the Board of Governors of the Federal Reserve from April 1951 to January 1970. During this period, the Fed used independence gained with the TreasuryFed Accord to begin a new regime for monetary policy, which chairman Martin described as "leaning against the wind." During this period, the FOMC began to use systematic 

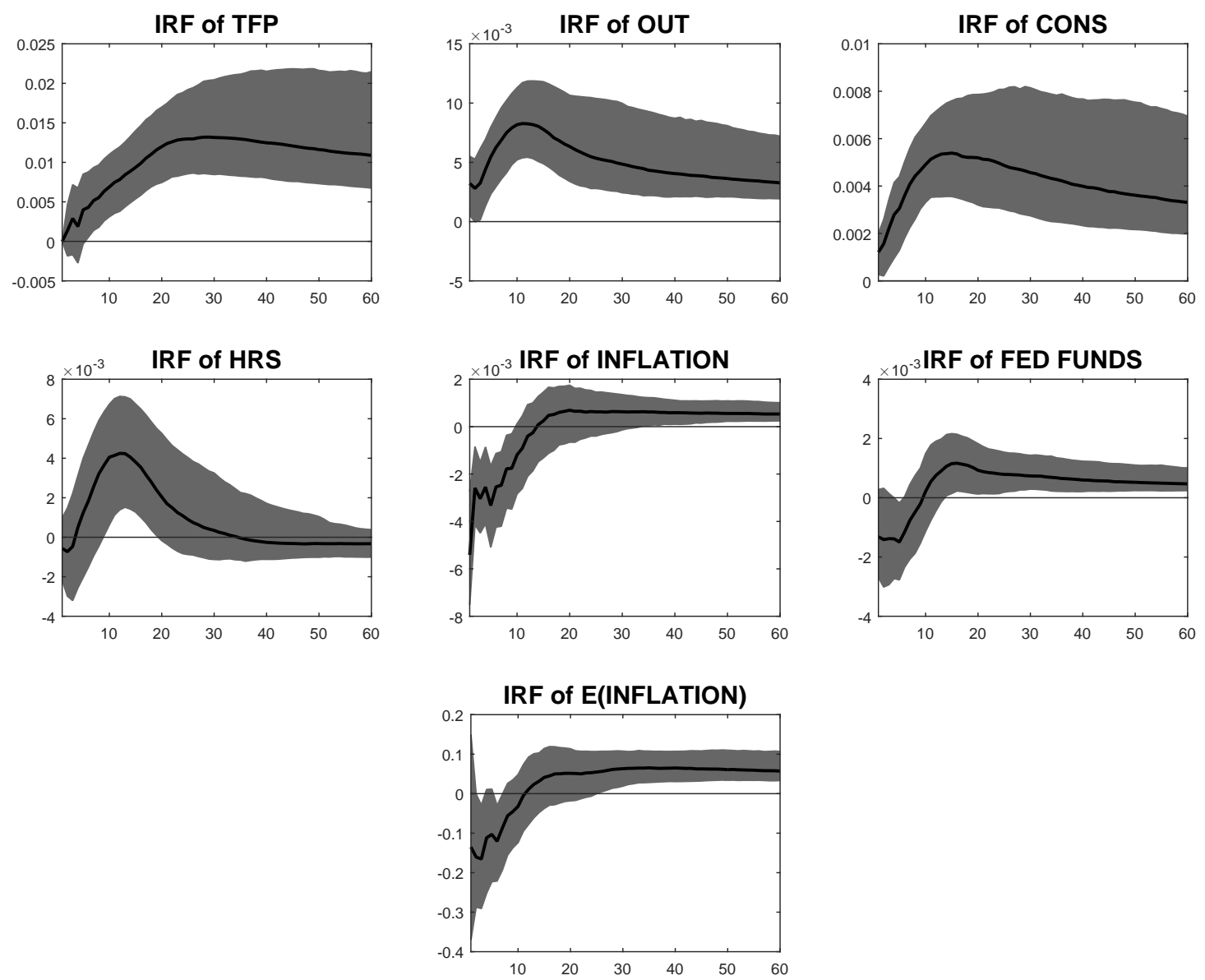

Figure 9: First sample (1954:Q3-1979:Q2). The solid line is the median estimated impulse response (in percent) to a positive TFP news shock from a seven variable VAR featuring TFP, output, consumption, hours, inflation, Fed Funds rate, and one-year-ahead Michigan inflation expectations estimated with four lags. Shaded areas indicate the $16 \%$ and $84 \%$ confidence bands. 

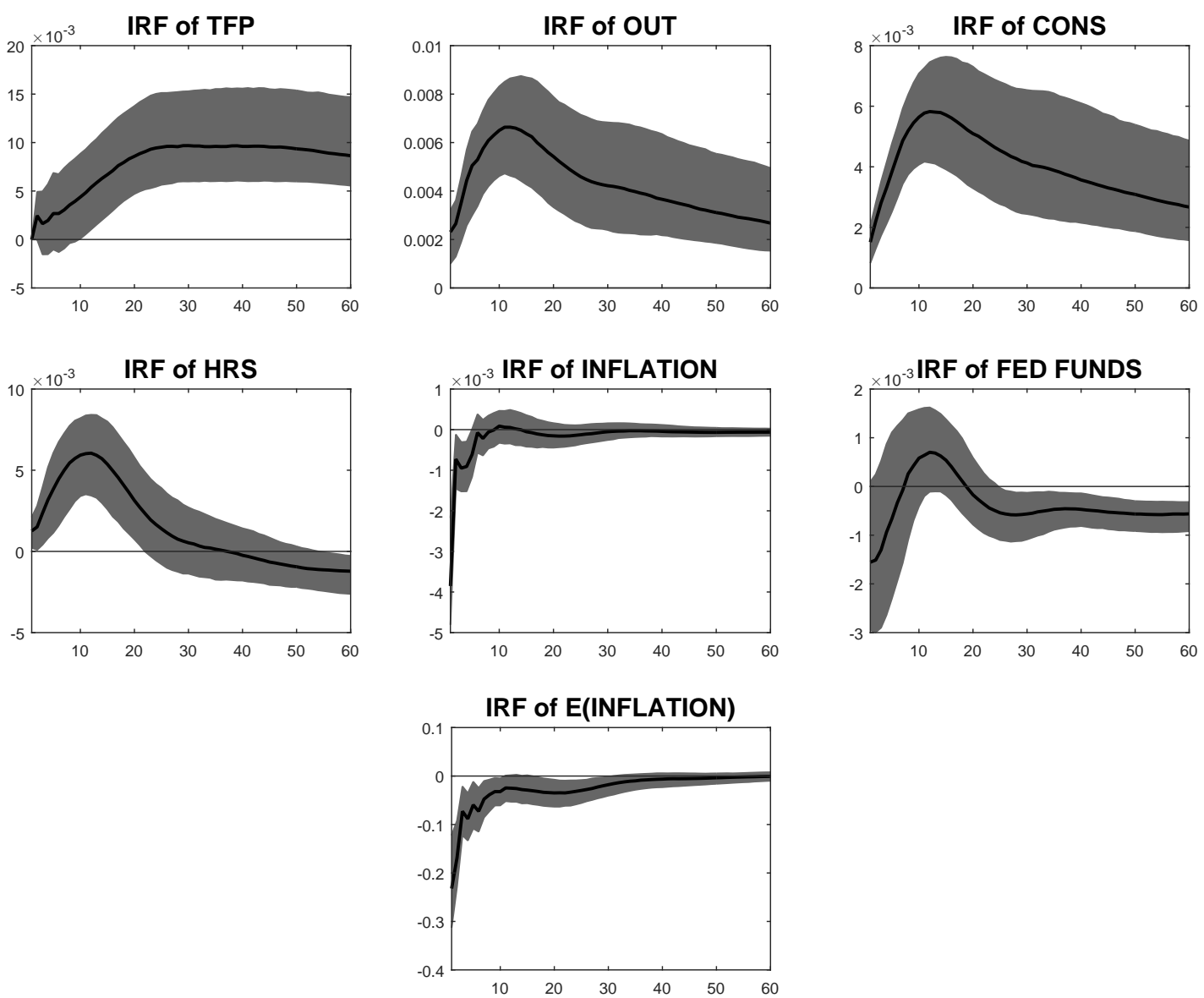

Figure 10: Second sample (1982:Q3-2013:Q4). The solid line is the median estimated impulse response (in percent) to a positive TFP news shock from a seven variable VAR featuring TFP, output, consumption, hours, inflation, Fed Funds rate, and one-year-ahead Michigan inflation expectations estimated with four lags. Shaded areas indicate the $16 \%$ and $84 \%$ confidence bands. 
changes in short-term interest rates to counteract unsustainable strength or weakness in economic activity. In the new policy regime, changes in short-term interest rates would be sharp enough to avert positive inflation premia in bond rates and upward pressures in inflation. The immediate responses in the VAR model of the policy rates to a raise in activity during the first subsample clearly indicate an active policy consistent with the new monetary policy regime. ${ }^{15}$ The conduct of monetary policy changes considerably in the second subsample. In August 1979, with the appointment of Paul Volcker as chairman of the Board of Governors of the Federal Reserve System, the Fed received a dual mandate to achieve maximum employment, stable prices and moderate long-term interest rates, becoming legally liable to maintain stable inflation. ${ }^{16}$ This commitment enabled the Fed to effectively anchor inflation expectations in the post-1980 period and coincided with a clear disinflationary period in the U.S. economy (see Goodfriend and King (2005)). ${ }^{17}$ Consistent with the VAR results in the post-1980s, the Fed allowed the nominal interest rate to decline in a quest to curb the fall in inflation since the Fed was able to credibly and effectively manage inflation expectations to restrain the rise in current inflation without having to increase the policy rate.

\footnotetext{
${ }^{15}$ As chairman, Martin was known for his tight money policies and anti-inflation bias. He emphasized the importance of statistics over economic theory and also pushed for flexibility and discretion in the Fed's policymaking. In 1956, he famously described the Fed's purpose to Congress as "leaning against the winds of deflation or inflation, whichever way they are blowing." See the chronicle of the Fed's history at: http://www.federalreservehistory.org/Events/DetailView/63, http://www.federalreservehistory.org/People/DetailView/113 and http://www.federalreservehistory.org/ Period/PrintView/12.

${ }^{16}$ The U.S. Congress introduced a dual mandate to promote maximum sustainable employment and price stability with the Federal Reserve Act of 1977.

${ }^{17}$ An array of studies supports this interpretation of monetary policy stance. See, for example, Gertler et al. (1999), Ireland (2007), Debortoli and Lakdawala (2016) and references therein.
} 


\section{Conclusion}

This paper documents significant changes in the effect of TFP news shocks on macroeconomic variables before and after 1980. Short- and long-term nominal interest rates exhibit a sign reversal in response to a news TFP shock before and after 1980. Using the Expectations Hypothesis, which conveys a broad appraisal on the overall expected stance of monetary policy, we document that the sign reversal also is echoed in the term structure of expected policy rates across subperiods. Specifically, our empirical analysis shows that the expectations component of long-term rates rises persistently in response to the anticipated increase in TFP in the pre-1980 period, and it declines persistently in the post-1980 period, suggesting a restrictive (accommodative) monetary policy stance in the pre-1980 (post-1980) period in response to the news TFP shock. Several activity variables also differ in their responses to the news shock across subperiods.

The analysis suggests that the different responses of macroeconomic aggregates to news shocks between subperiods are related to sharp changes in the conduct of monetary policy. Systematic policy changes are reflected by the ineffectiveness of the Fed to anchor inflation expectations in the pre-1980 period and the subsequent strong objective to achieve stable inflation that leads to a powerful anchoring of inflation expectations in the post-1980 period. Thus, the Fed's weak influence over the formation of expectations in the first subperiod leads to a tightening of monetary policy in response to any initial increase in economic activity in consequence of the news shock. By contrast, the Fed adopts a loosening monetary policy in the second subperiod since it can credibly and effectively manage inflation expectations to restrain the rise in inflation that results from the increase in real activity generated by the news shock.

Our study offers several interesting directions for future research. It would certainly be valuable to develop structural models to study the interaction between the formation 
of expectations and systematic changes in the conduct of monetary policy, which is a central finding of our analysis. Such models should incorporate imperfect common knowledge of economic agents that recent studies find capable of generating a reversal in the response of the economy to aggregate disturbances. ${ }^{18}$ Disperse information is also a critical feature to include in the model since it may interact with monetary policy to explain changes in the propagation of anticipated news shocks, as Melosi (2014) shows for the propagation of monetary and technology shocks. These important extensions remain open to future research.

${ }^{18}$ See Melosi (2016) and references therein for a recent discussion of the issues. 


\section{References}

Barsky, R. B., Basu, S., and Lee, K. (2015). Whither News Shocks? NBER Macroeconomics Annual, 29(1):225 - 264.

Barsky, R. B. and Sims, E. R. (2011). News shocks and business cycles. Journal of Monetary Economics, 58(3):273-289.

Basu, S., Fernald, J., Fisher, J., and Kimball, M. (2010). Sector specific technical change. Mimeo.

Basu, S., Fernald, J., and Kimpball, M. (2006). Are technology improvements contractionary? American Economic Review, 96(5):1418-1448.

Beaudry, P. and Portier, F. (2004). An exploration into Pigou's theory of cycles. Journal of Monetary Economics, 51(6):1183-1216.

Beaudry, P. and Portier, F. (2006). News, stock prices and economic fluctuations. The American Economic Review, 96(4):1293-1307.

Beaudry, P. and Portier, F. (2014). News-Driven Business Cycles: Insights and Challenges. Journal of Economic Literature, 52(4):993-1074.

Ben Zeev, N. and Khan, H. (2015). Investment Specific News Shocks and U.S. Business Cycles. Journal of Money, Credit and Banking, 47(7):1443-1464.

Benati, L. (2004). Evolving post World War II U.K. economic performance. Journal of Money, Credit and Banking, 36(1):pp. 691-717.

Bianchi, F., Mumtaz, H., and Surico, P. (2009). The Great Moderation of the term structure of UK interest rates. Journal of Monetary Economics, 56(6):856-871. 
Boivin, J. and Giannoni, M. P. (2006). Has Monetary Policy Become More Effective? The Review of Economics and Statistics, 88(3):445-462.

Castelnuovo, E. (2012). Estimating the Evolution of Moneys Role in the U.S. Monetary Business Cycle. Journal of Money, Credit and Banking, 44(1):23-52.

Christiano, L. J., Ilut, C., Motto, R., and Rostagno, M. (2010). Monetary policy and stock market booms. Proceedings Economic Policy Symposium Jackson Hole, pages $85-145$.

Clarida, R., Gal, J., and Gertler, M. (2000). Monetary policy rules and macroeconomic stability: evidence and some theory. Quarterly Journal of Economics, 115:147-180.

Debortoli, D. and Lakdawala, A. (2016). How Credible Is the Federal Reserve? A Structural Estimation of Policy Re-optimizations. American Economic Journal: Macroeconomics, 8(3):42-76.

Faust, J., Gilchrist, S., Wright, J. H., and Zakrajšsek, E. (2013). Credit spreads as predictors of real-time economic activity: a Bayesian model-averaging approach. Review of Economics and Statistics, 95(5):1501-1519.

Fernald, J. (2012). A quarterly, utilization-adjusted series on total factor productivity. Working Paper, (2012-19).

Forni, M., Gambetti, L., and Sala, L. (2014). No News in Business Cycles. Economic Journal, 124(581):1168-1191.

Fujiwara, I., Hirose, Y., and Shintani, M. (2011). Can news be a major source of aggregate fluctuations? A Bayesian DSGE approach. Journal of Money, Credit and Banking, 43(1):1-29. 
Gambetti, L. and Gali, J. (2009). On the Sources of the Great Moderation. American Economic Journal: Macroeconomics, 1(1):26-57.

Gertler, M., Gali, J., and Clarida, R. (1999). The Science of Monetary Policy: A New Keynesian Perspective. Journal of Economic Literature, 37(4):1661-1707.

Gilchrist, S. and Zakrajek, E. (2012). Credit spreads and business cycle fluctuations. American Economic Review, 102(4):1692-1720.

Gilchrist, S. and Zakrajsek, E. (2012). Credit spreads and business cycle fluctuations. American Economic Review, 102(4):1692-1720.

Goodfriend, M. and King, R. G. (2005). The incredible Volcker disinflation. Journal of Monetary Economics, 52(5):981-1015.

Görtz, C. and Tsoukalas, J. (2017). News and financial intermediation in aggregate fluctuations. Review of Economics and Statistics, 99:514-530.

Görtz, C., Tsoukalas, J. D., and Zanetti, F. (2016). News Shocks under Financial Frictions. Economics Series Working Papers 813, University of Oxford, Department of Economics.

Ireland, P. N. (2000). Interest Rates, Inflation, and Federal Reserve Policy since 1980. Journal of Money, Credit and Banking, 32(3):417-434.

Ireland, P. N. (2003). Endogenous money or sticky prices? Journal of Monetary Economics, 50(8):1623-1648.

Ireland, P. N. (2007). Changes in the Federal Reserve's Inflation Target: Causes and Consequences. Journal of Money, Credit and Banking, 39(8):1851-1882. 
Karnizova, L. (2010). The spirit of capitalism and expectation-driven business cycles. Journal of Monetary Economics, 57(6):739-752.

Kurmann, A. and Otrok, C. (2013). News shocks and the slope of the term structure of interest rates. American Economic Review, 103:2612-2632.

Liu, P., Mumtaz, H., Theodoridis, K., and Zanetti, F. (2017). Changing Macroeconomic Dynamics at the Zero Lower Bound. Economics Series Working Papers 824, University of Oxford, Department of Economics.

Melosi, L. (2014). Estimating models with dispersed information. American Economic Journal: Macroeconomics, 6(1):1-31.

Melosi, L. (2016). Signalling effects of monetary policy. The Review of Economic Studies, 84(2):853-884.

Milani, F. (2011). Expectation shocks and learning as drivers of the business cycle. The Economic Journal, 121(552):379-401.

Mumtaz, H. and Surico, P. (2012). Evolving International Inflation Dynamics: World And Country-Specific Factors. Journal of the European Economic Association, 10(4):716-734.

Neville, F., Owyang, M., Roush, J., and DiCecio, R. (2014). A flexible finite-horizon alternative to long-run restrictions with an application to technology shocks. Review of Economics and Statistics, 96:638-647.

Pigou, A. C. (1926). Industrial Fluctuations. Macmillan. London.

Schmitt-Grohe, S. and Uribe, M. (2012). What's news in business cycles? Econometrica, 80(6):2733-2764. 
Svensson, L. E. (2010). Inflation Targeting. In Friedman, B. M. and Woodford, M., editors, Handbook of Monetary Economics, volume 3 of Handbook of Monetary Economics, chapter 22, pages 1237-1302. Elsevier.

Taylor, J. B. (1993). Discretion versus policy rules in practice. Carnegie-Rochester Conference Series on Public Policy, 39(1):195-214.

Theodoridis, K. and Zanetti, F. (2016). News shocks and labour market dynamics in matching models. Canadian Journal of Economics, 49(3):906-930.

Uhlig, H. (2004). What moves GNP? Econometric Society 2004 North American Winter Meetings 636, Econometric Society. 


\section{Appendix}

\section{A Data Sources and Time Series Construction}

Table 1 provides an overview of the data used in the analysis. Below we describe in detail all of the data transformations we made to construct the dataset for the estimation of the VAR model. We take the data series for aggregate utilization adjusted TFP to estimate the VARs from John Fernald's website (www.frbsf.org/economic research/economists/jfernald/quarterly_tfp.xls), as described in Fernald (2012).

Table 1: Time Series used in the empirical analysis

\begin{tabular}{|c|c|c|c|}
\hline Time Series Description & Units & Code & Source \\
\hline Gross domestic product & $\mathrm{CP}, \mathrm{SA}$, billion $\$$ & GDP & BEA \\
\hline Gross Private Domestic Investment & $\mathrm{CP}, \mathrm{SA}$, billion $\$$ & GPDI & BEA \\
\hline Real Gross Private Domestic Investment & CVM, SA, billion $\$$ & GPDIC1 & BEA \\
\hline Personal Consumption Exp.: Durable Goods & $\mathrm{CP}, \mathrm{SA}$, billion $\$$ & PCDG & BEA \\
\hline Real Personal Consumption Exp.: Durable Goods & CVM, SA, billion $\$$ & PCDGCC96 & BEA \\
\hline Personal Consumption Expenditures: Services & $\mathrm{CP}, \mathrm{SA}$, billion $\$$ & PCESV & BEA \\
\hline Real Personal Consumption Expenditures: Services & CVM, SA, billion $\$$ & PCESVC96 & BEA \\
\hline Personal Consumption Exp.: Nondurable Goods & $\mathrm{CP}, \mathrm{SA}$, billion $\$$ & PCND & $\mathrm{BEA}$ \\
\hline Real Personal Consumption Exp.: Nondurable Goods & CVM, SA, billion $\$$ & PCNDGC96 & BEA \\
\hline Civilian Noninstitutional Population & NSA, $1000 \mathrm{~s}$ & CNP160V & BLS \\
\hline Non-farm Business Sector: Compensation Per Hour & SA, Index $2005=100$ & COMPNFB & BLS \\
\hline Non-farm Business Sector: Hours of All Persons & SA, Index $2005=100$ & HOANBS & BLS \\
\hline Effective Federal Funds Rate & NSA, percent & FEDFUNDS & $\mathrm{BG}$ \\
\hline 3 Month Treasury Bill Rate & NSA & T-Bill & St. Louis FED FRED \\
\hline 1 Year, 5 Year, 10 Year government bond Yields & NSA & & Fed Board \\
\hline All Employees & SA & B-1 & BLS \\
\hline Average Weekly Hours & SA & B-7 & BLS \\
\hline E5Y Confidence Indicator & & Table 29 & Michigan Survey \\
\hline Buy Intentions Durables & & Table 35 & Michigan Survey \\
\hline Buy Intentions Vehicles 1 Year ahead & & Table 37 & Michigan Survey \\
\hline Buy Conditions Housing & & Table 41 & Michigan Survey \\
\hline BAA-AAA corporate spread & & & St. Louis FED FRED \\
\hline
\end{tabular}

$\mathrm{CP}=$ current prices, $\mathrm{CVM}=$ chained volume measures $(2005$ Dollars), $\mathrm{SA}=$ seasonally adjusted, NSA = not seasonally adjusted. BEA = U.S. Department of Commerce: Bureau of Economic Analysis, BLS = U.S. Department of Labor: Bureau of Council, FRB $=$ Federal Reserve Board.

Real and nominal variables. Consumption (in current prices) is defined as 
the sum of personal consumption expenditures on services and personal consumption expenditures on non-durable goods. The time series for real consumption is constructed as follows. First, we compute the shares of services and non-durable goods in total (current price) consumption. Then, total real consumption growth is obtained as the chained weighted (using the nominal shares above) growth rate of real services and growth rate of real non-durable goods. Using the growth rate of real consumption, we construct a series for real consumption using 2005 as the base year. The consumption deflator is calculated as the ratio of nominal over real consumption. In the VAR model, we use the log change in the GDP deflator as our inflation measure; however results are nearly identical when we use the consumption deflator or CPI inflation. Analogously, we construct a time series for the investment deflator using series for (current price) personal consumption expenditures on durable goods and gross private domestic investment and chain weight to arrive at the real aggregate. Real output is GDP expressed in consumption units by dividing current price GDP with the consumption deflator.

The hourly wage is defined as total compensation per hour. Dividing this series by the consumption deflator yields the real-wage rate. Hours worked is given by hours of all persons in the non-farm business sector. All series described above are expressed in per capita terms using the series of non-institutional population, age 16 and above.

The BAA-AAA spread. The spread is obtained from the Federal Reserve Bank of St. Louis' online database FRED (https : //fred.stlouisfed.org.).

Tobin's Q. Tobin's Q is the ration of market to book value for the Dow Jones Industrial Average. This definition is taken directly from Welsh and Goyal (2008), "A Comprehensive Look at The Empirical Performance of Equity Premium Prediction," Review of Financial Studies, 21. 


\section{B Specification for the Minnesota prior in the VAR}

Assume the simple $\operatorname{VAR}(p)$ model

$$
y_{t}=v+A_{1} y_{t-1}+\ldots+A_{p} y_{t-p}+\varepsilon_{t},
$$

where $y_{t}$ is a $n \times 1$ vector of variables, and $\varepsilon_{t} \sim N(0, \Sigma)$ with $\Sigma$ the covariance matrix.

The prior for the VAR coefficients $A=\left[v, A_{1}^{\prime}, \ldots, A_{p}^{\prime}\right]^{\prime}$ is of the form

$$
\operatorname{vec}(A) \sim N(\underline{\beta}, \underline{V}),
$$

where $\underline{\beta}$ is one for variables that are in log-levels, and zero for rate variables (inflation, short and long interest rates). The prior variance $\underline{V}$ is diagonal with elements,

$$
\underline{V}_{i, j j}=\left\{\begin{array}{l}
\frac{\underline{a}_{1}}{p^{2}} \text { for coefficients on own lags } \\
\frac{a_{2} \sigma_{i i}}{p^{2} \sigma_{j j}} \text { for coefficients on lags of variable } j \neq i \\
\underline{a}_{3} \sigma_{i i} \text { for intercepts }
\end{array}\right.
$$

where, $p$ denotes the number of lags. Here $\sigma_{i i}$ is the residual variance from the unrestricted $p$-lag univariate autoregression for variable $i$. The degree of shrinkage depends on the hyperparameters $\underline{a}_{1}, \underline{a}_{2}, \underline{a}_{3}$. We set $\underline{a}_{3}=100$, and we select $\underline{a}_{1}, \underline{a}_{2}$ by specifying a wide grid of possible values ${ }^{19}$. We take all possible pairs of $\underline{a}_{1}$ and $\underline{a}_{2}$ on these grids, thus, estimating 1540 models with varying degrees of prior informativeness. The optimal shrinkage pair for $\underline{a}_{1}$ and $\underline{a}_{2}$ is the one that maximizes the in-sample fit of the VAR, as measured by the Bayesian Information Criterion. The covariance matrix has a diffuse prior of the form $p(\Sigma) \propto|\Sigma|^{-(n+1) / 2}$.

\footnotetext{
${ }^{19}$ The grids of values we use are: $\underline{a}_{1}=(1 \mathrm{e}-5,2 \mathrm{e}-5,3 \mathrm{e}-5,4 \mathrm{e}-5,5 \mathrm{e}-5,6 \mathrm{e}-5,7 \mathrm{e}-5,8 \mathrm{e}-5,9 \mathrm{e}-5,1 \mathrm{e}-4,2 \mathrm{e}-4,3 \mathrm{e}-4,4 \mathrm{e}-$ $4,5 \mathrm{e}-4,6 \mathrm{e}-4,7 \mathrm{e}-4,8 \mathrm{e}-4,9 \mathrm{e}-4,0.001,0.002,0.003,0.004,0.005,0.006,0.007,0.008,0.009,0.01,0.02,0.03,0.04,0.05,0.06$, $0.07,0.08,0.09,0.1,0.2,0.3,0.4,0.5,0.6,0.7,0.8,0.9,1,2,3,4,5,6,7,8,9,10)$, $\underline{a}_{2}=(0.01,0.02,0.03,0.04,0.05,0.06,0.07,0.08,0.09,0.1,0.2,0.3,0.4,0.5,0.6,0.7,0.8,0.9,1,2,3,4,5,6,7,8,9,10)$.
} 


\section{Forward-looking variables}

Do responses to forward-looking variables across the two sub-samples show any systematic change related to the variation in the responses of series of economic activity and interest rates? Figures 11 and 12 show the responses of several expectation indicators from the Michigan Survey of Consumers and Tobin's Q. Tobin's Q refers to the ratio of market value to book value of companies in the Dow Jones Industrial average, and it is a key forward-looking measure of how financial markets assess profitability in modern investment theory. In the first subperiod, the response of consumer confidence (E5Y) is insignificant on impact, only becoming significantly positive after one year. In the second subperiod, by contrast, the response of consumer confidence is strongly and persistently positive at all horizons, suggesting confidence about expansionary prospects of the economy. This response is interesting despite some delay in the rise of TFP (not shown here). We examine the behavior of three other confidence indicators from the Michigan survey that are highly representative of the consumers' perception about future economic conditions, namely buying conditions for consumer durables, housing and vehicles. In the first subperiod, none of the responses of buying conditions for consumer durables, housing or vehicles is significantly different from zero. By contrast, in the second subperiod, the responses are strongly positive and significant, suggesting that consumers perceive good times ahead. The response of Tobin's Q also is quite different quantitatively across subperiods. Tobin's Q is a key summary statistic for private investment spending because it incorporates future expectations about corporate profitability and captures how the stock market values capital of the corporate sector. While the response of the Tobin's Q is qualitatively similar across horizons in both subperiods, the response in the first subperiod is insignificant on impact. By contrast, the response in the second subperiod is approximately four times larger than the first 
subperiod.
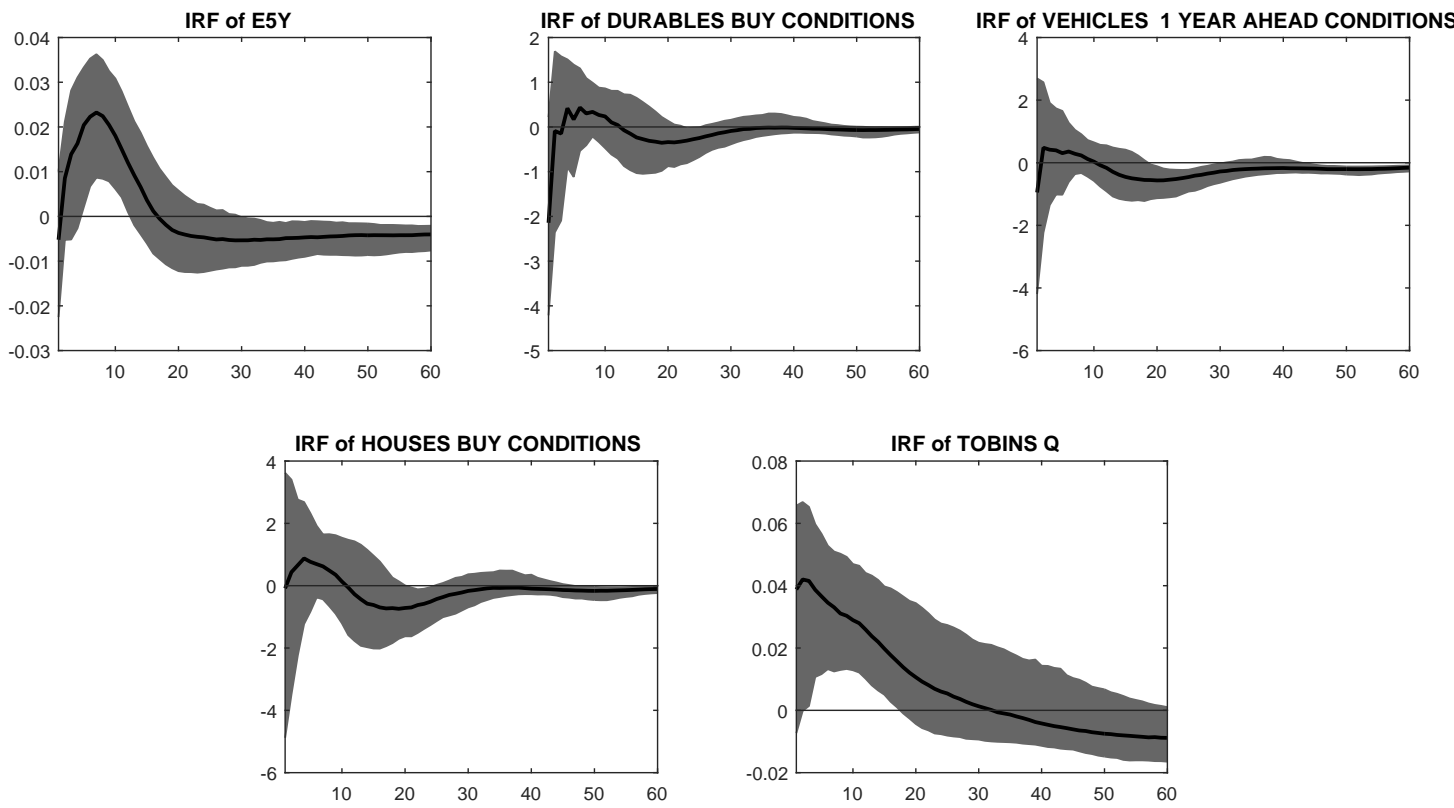

Figure 11: First sample (1954:Q3-1979:Q2)-Michigan surveys and Tobin's Q. The solid line is the median estimated impulse response (in percent) to a positive TFP news shock. Shaded areas indicate the $16 \%$ and $84 \%$ confidence bands. 

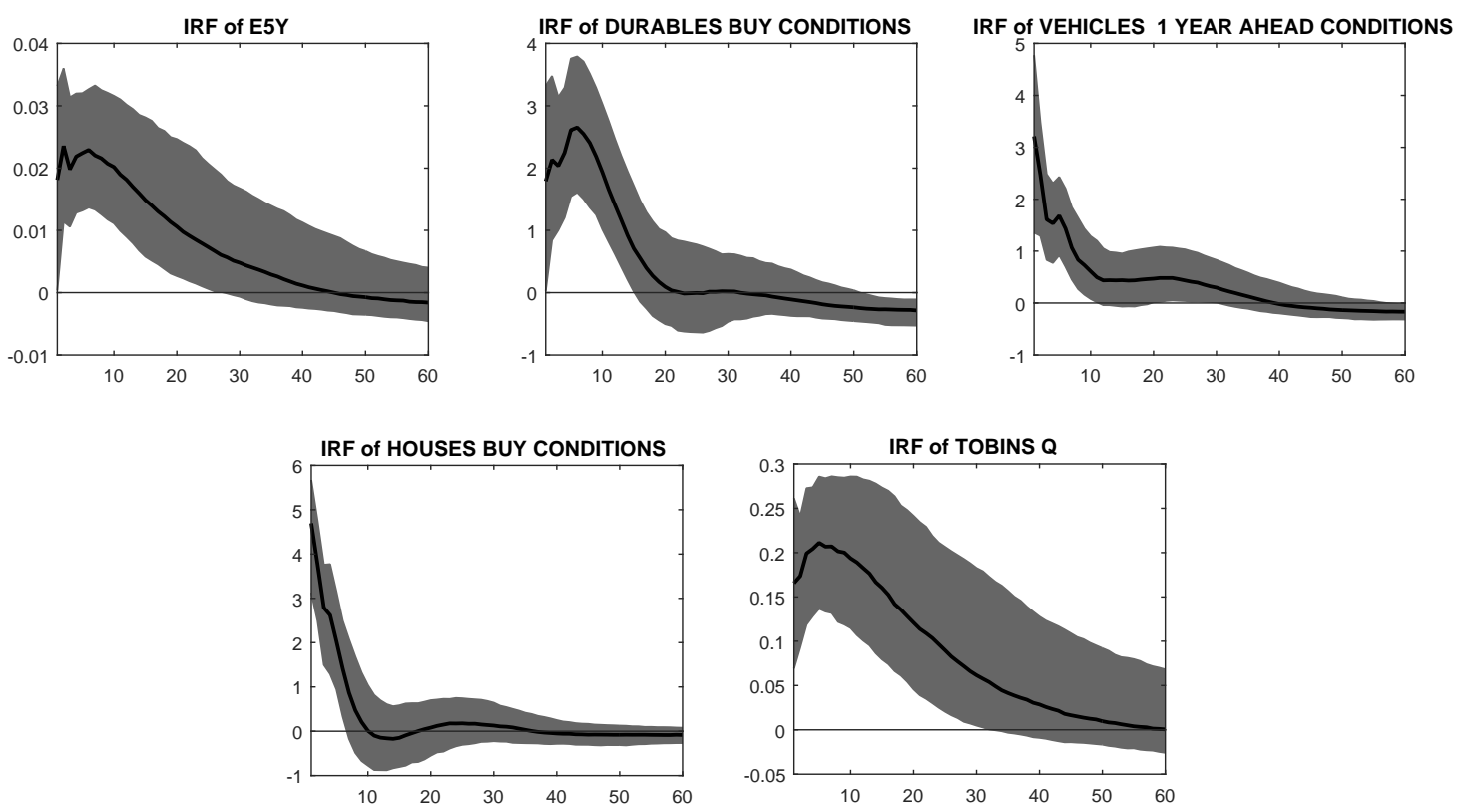

Figure 12: Second sample (1982:Q3-2013:Q4)-Michigan surveys and Tobin's Q. The solid line is the median estimated impulse response (in percent) to a positive TFP news shock. Shaded areas indicate the $16 \%$ and $84 \%$ confidence bands. 